\title{
The Mass Spectrometry of Helical Unfolding in Peptides
}

\author{
Robert J. Anderegg, David S. Wagner, and Cynthia L. Stevenson \\ Glaxo Research Laboratories, Research Triangle Park, North Carolina, USA
}

\author{
Ronald T. Borchardt \\ Department of Pharmaceutical Chemistry, University of Kansas, Lawrence, Kansas, USA
}

\begin{abstract}
Two model peptides, melittin and a growth hormone releasing factor (GRF) analog, have been studied by mass spectrometry and tandem mass spectrometry during the course of their deuterium exchange. Both peptides are known from previous work to form $\alpha$-helices in solution. When the peptides are exposed to deuterated solvents, their masses increase as deuterium atoms replace protons in the exchangeable sites of the peptides. The mass spectrometry results clearly indicate multiple populations of exchangeable protons: Some exchange very fast, and are presumably on the surface and not involved in hydrogen bonding; others exchange much more slowly, indicating that they are probably participating in hydrogen bonding.

Tandem mass spectrometric experiments were conducted, and the masses of the product (fragment) ions were used to determine where in the peptide the deuterium atoms were incorporated. The results agree very well with NMR studies of the same peptides. Melittin. appears as two helical segments with a kink around Pro-14. The GRF analog contains a single long helix, spanning almost the entire length of the peptide. The dynamics of the unfolding of the helices can also be explored by observing how the exchange progresses with time. (7 Am Soc Mass Spectrom 1994, 5, 425-433).
\end{abstract}

$\mathrm{B}$ ioactive peptides frequently exert their influence as a consequence of their secondary structure. It is well established that primary sequences or solution conditions that alter the local folding of peptides can disrupt bioactivity [1-3]. Peptide secondary structure is generally studied spectroscopically using circular dichroism (CD) or NMR [4]. CD provides a time-averaged picture of percent helicity, for example, but can give no information regarding the precise location of the helix, nor of its stability.

Hydrogen/deuterium exchange can provide important information about both the location and the stability of secondary structure. These experiments are 11sually followed by NMR as the rate of disappearance of the proton resonance signal [5]. Precise location of secondary features by NMR requires the complete assignment of the resonances under observation. Recently, mass spectrometry has been shown to be useful for following hydrogen/deuterium exchange in proteins [6-9] and peptides [10-11]. Although these methods provide information on solution conformation [6, 7. 10, 11] gas phase conformation [8], or transient folding populations [9], they only measure global ex-

Address reprint requests to Robert J. Anderegg, Glaxo Research Laboratories, 5 Moore Drive, Research Triangle Park, NC 27709. change levels; the change in mass of the peptide gives no precise information about the location of the deuterium atoms.

We are exploring the use of tandem mass spectrometry (MS/MS) to follow the deuterium exchange of a series of model peptides. The peptides described here are known to adopt a helical conformation under the solution conditions used without the complication of other types of secondary structure. We were interested to see if the mass shift of sequence-specific fragment ions could be used to identify where the deuterium atoms were exchanging. Knowing the location of the deuterium atoms would allow us to infer where hydrogen bonds existed in the peptides, and hence where regions of helix were likely to be. The time course of the exchange should also provide information about the stability of the helix over time. The results on two such systems, melittin and a growth hormone releasing factor (GRF) analog, are very encouraging.

\section{Experimental}

The deuterated solvents: deuterium oxide, methanol, and acetic acid used in this study $\left(\mathrm{D}_{2} \mathrm{O}, 99.9 \% ; \mathrm{CD}_{3} \mathrm{OD}\right.$, 99.9\%; and $\mathrm{CD}_{3} \mathrm{CO}_{2} \mathrm{D}, 99.8 \%$ ), were purchased from Cambridge Isotopes (Woburn, MA). Melittin was pur- 
chased from Sigma (St. Louis, MO) and was used without further purification. The $\mathrm{Ala}^{15}, \mathrm{Leu}^{27}$-bovine GRF (1-32) $\mathrm{NH}_{2}$ (Ala-bGRF) was generously supplied by the UpJohn Company (Kalamazoo, MI).

Electrospray ionization (ESI) mass spectra were collected in a Sciex API-III mass spectrometer (Sciex, Thornhill, Ontario) in the positive ion mode. A Harvard model 22 syringe pump (Harvard Apparatus, South Natick, MA) was used to infuse the samples into the instrument at a rate of $2 \mu \mathrm{l} / \mathrm{min}$. The ion spray needle was maintained at $5300 \mathrm{~V}$, and the orifice potential was $80 \mathrm{~V}$. Measured molecular masses are reported \pm the standard deviation derived from all observed charge states.

The mass spectrometry samples were lyophilized to dryness to ensure the deuterium atoms did not have competition from residual solvent protons. The deuterated solvent, $\mathrm{CD}_{3} \mathrm{OD}: \mathrm{D}_{2} \mathrm{O}: \mathrm{CD}_{3} \mathrm{CO}_{2} \mathrm{D}$ (80:20:2), was added to the dried peptide sample to give a final concentration of $5 \mu \mathrm{M}$; and the solution was introduced into the mass spectrometer as quickly as possible (10-20 s). To minimize back exchange, the syringe and transfer line to the electrospray needle were equilibrated with the same deuterated solvent for at least 30 min prior to sample introduction. The mass range was adjusted to include a region surrounding the +4 charge state for each peptide and the total scan time was $4.2 \mathrm{~s}$ per scan. Scanning was initiated at the same time as sample dissolution so that the time axis in the mass spectrometric experiment also corresponded to the time of exposure to deuterated solvent. The data for the +4 charge state was then converted to average molccular mass of the peptide and plotted as a function of time.

MS/MS experiments were conducted by operating MS-1 in a defocused mode that allowed the transmission of a broad range of mass-to-charge ratio (10-15 Da) surrounding the precursor ion of interest, usually the +4 charge state. Precursor ions were collisionally activated by collision with argon:nitrogen (9:1) at a gas thickness of $6 \times 10^{15}$ molecules $\mathrm{cm}^{2}$ (CGT setting $=$ 600). Product ions were detected at unit mass resolution by scanning MS-2. The mass-to-charge ratio range between 100 and 1300 was scanned continuously with a 0.2 Da step size and $0.7 \mathrm{~ms}$ dwell time, giving rise to a total scan time of $4.2 \mathrm{~s}$. In order to obtain quality data for each scan in MS/MS experiments, the peptide concentration was increased to $20 \mu \mathrm{M}$.

The ionization chamber of the mass spectrometer was enclosed and continually flushed with nitrogen ( 8 $\mathrm{L} / \mathrm{min}$ ) to prevent the fast exchanging deuterium atoms from re-exchanging with $\mathrm{H}_{2} \mathrm{O}$ in the laboratory air. It is important to note that the deuterium exchange reactions were taking place in the solution phase and were being analyzed in the gas phase. The degree of deuterium incorporation was measured as the peptide's mass increased during an experiment.

The nominal $\mathrm{pH}$ of the solutions was measured with a standard glass electrode that had been previously calibrated with aqueous solutions.

\section{Results and Discussion}

In order to develop methods to study secondary structure of peptides by electrospray ionization mass spectrometry (ESI/MS), we selected two well-characterized peptide systems. Melittin, a 26-residue peptide from bee venom, is known to adopt a helical structure in organic or high ionic strength aqueous solutions [12-13]. GRFs are hypothalamic peptides with a potential use as a therapy for growth hormone deficiency [14]. GRF also adopts a helical conformation, particularly in organic solvents, as evidenced by both NMR and modeling studies [15-18]. The sequences of melittin and the bovine GRF analog (Ala-bGRF) we used are shown in Scheme I.

\section{Mass Spectrometry}

The ESI mass spectra of melittin and Ala-bGRF are shown in Figure 1. ESI/MS spectra are characterized by a series of ions differing in the number of charges

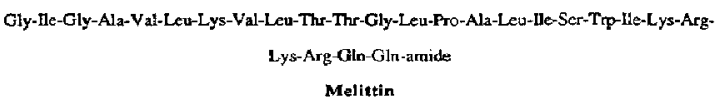

Tyr-Ala-Asp-Ala-Ile-Phe-Thr-Asn-Ser-Tyr-Arg-Lys-Val-Leu-Ala-Gln-Leu-Ser-Ala-Arg-Lys-LeuLeu-Gin-Asp-Ile-Let-Asn-Arg-Gin-Gin-Gly-amide Ala-bGRF

Scheme I
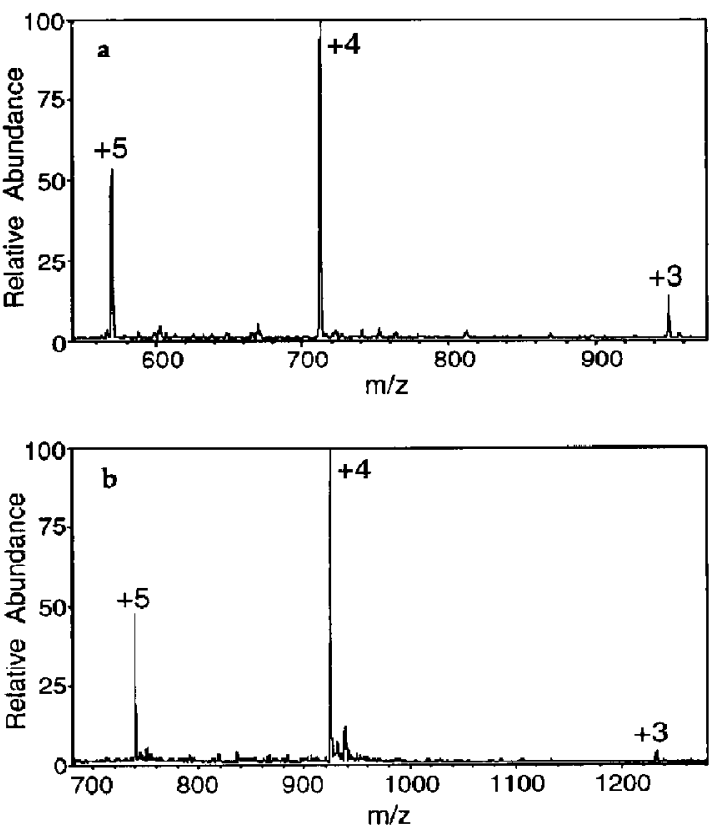

Figure 1. ESI mass spectra of melittin (a) and Ala-bGRF (b) in methanol:water:acetic acid $(80: 20: 2)$. 
carried by the molecule [19-20]. Both the mass of the peptide and charge state of the ions can be calculated [21]. The measured molecular masses for melittin and Ala-bGRF were $2846.0 \pm 0.4$ and $3693.9 \pm 0.1$, respectively, where the errors indicate the standard deviation of the mass estimates from all observed charge states. These values are in good agreement with the values predicted from their amino acid sequences (2846.5 and 3694.2). Both peptides gave rise to a prominent +4 charged ion that was used to monitor deuterium exchange and as a precursor for subsequent MS/MS experiments.

When the peptide was exposed to deuterated solvents, the observed mass increased rapidly as deuterium atoms replaced protons. The exchangeable protons in the amino acid side chains are freely accessible to solvent and would be expected to exchange almost instantaneously; protons involved in hydrogen bonding would exchange somewhat more slowly, giving rise to a time-dependent mass profile as illustrated for melittin in Figure 2.

Melittin has 22 exchangeable side chain protons, 4 terminal protons $\left(\mathrm{H}_{2} \mathrm{~N}\right.$ and $\left.\mathrm{CONH}_{2}\right)$, and 24 amide protons that can exchange $e_{r}$ for a total of 50 exchangeable sites. Upon complete deuteration, the molecular mass would be expected to change from 2846 to 2896 . The information obtained from the experiment described in Figure 2 can be converted to exchange rate information by replotting it as $\ln \left(\mathrm{H}_{\mathrm{t}}\right)$ as a function of time, where $H_{t}$ represents the number of protons that have not yet exchanged at any given time, t. Populations of protons that have similar first-order rate constants will be represented in such a plot as a straight line with slope inversely proportional to the rate constant, $\mathbf{k}$. The exchange data for melittin are shown in this format in Figure 3a. Three linear regions of the

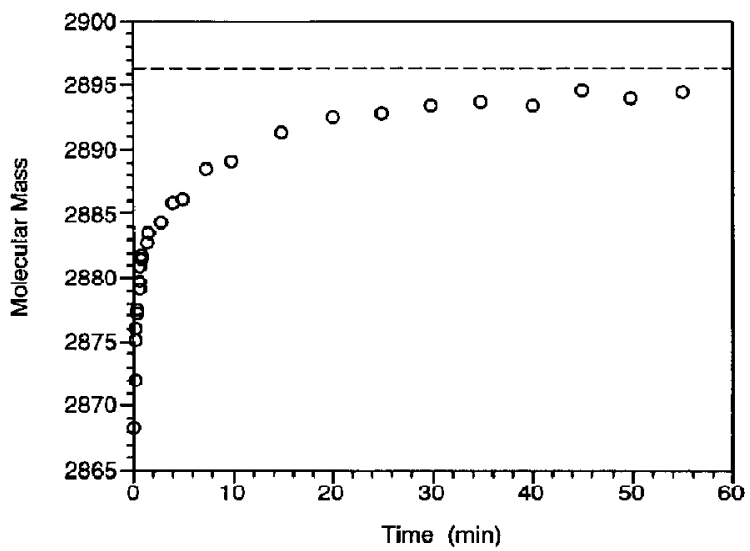

Figure 2. Time course of molecular mass increase of melittin upon exposure to $\mathrm{CD}_{3} \mathrm{OD}: \mathrm{D}_{2} \mathrm{O}: \mathrm{CD}_{3} \mathrm{CO}_{2} \mathrm{D}(80: 20: 2)$. The +4 charged ion was monitored $(m / z, 712)$ and then converted to a molecular mass by multiplying by four and subtracting eight (the mass of four deuterium atoms). The dashed line indicates the expected molecular mass of the fully deuterated peptide:
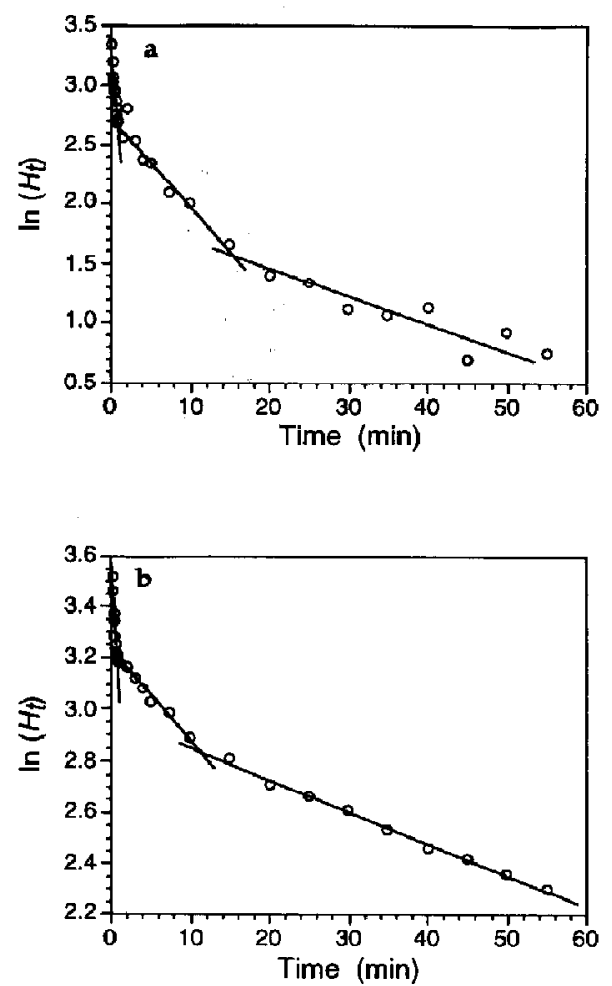

Figure 3. Time-dependent decrease in $\ln \left(\mathrm{H}_{\mathrm{t}}\right)$, the natural logarithm of the number of protons not yet exchanged in melittin (a) and Ala-bGRF (b). Lines indicate best-fit linear regression curves for various regions of the plot and probably represent populations of protons exchanging with similar rates.

plot are observed. From 0.3 to $0.8 \mathrm{~min}$, the data can be represented by the line: $y=3.4-0.88 t\left(r^{2}=0.980\right)$. This would be consistent with a group of protons exchanging with a half-life of about $47 \mathrm{sec}$. Between 1 and $20 \mathrm{~min}$ of exchange, the rate slows dramatically. The linear region here is described by $\mathrm{y}=2.7-0.071 \mathrm{t}$ $\left(r^{2}=0.981\right)$, corresponding to a population exchanging with a half-life of $10 \mathrm{~min}$. After $20 \mathrm{~min}$, there are very few protons not exchanged; but the region between 20 and $50 \mathrm{~min}$ is represented by the line $\mathrm{y}=1.7-0.019 \mathrm{t}$ $\left(\mathrm{r}^{2}=0.899\right)$, corresponding to a population with a half-life of $37 \mathrm{~min}$.

We interpret these linear regions in terms of the peptide secondary structure. Even at $\mathrm{pH} 3.2$ (the measured $\mathrm{pH}$ of the deuterated solvent mixture) the intrinsic exchange rate of most side-chain protons is very fast. The fastest exchanging protons are likely to be those not involved in stabilizing secondary structure. If protons are involved in hydrogen bonding, the rate of exchange slows significantly [5]. The hydrogen bonds must be broken before exchange with solvent can take place. The protons we observe exchanging with halflives of 10 or $37 \mathrm{~min}$ are very likely to be those involved in hydrogen bonds. 
A similar analysis can be done for the Ala-bGRF exchange (Figure $3 \mathrm{~b}$ ). Ala-bGRF has 31 amide protons, 4 terminal protons, and 35 exchangeable side-chain protons; the mass would be expected to change from 3695 to 3765 upon deuteration. As with melittin, there are three regions of the plot (Figure $3 b$ ) that approach linearity. The first $0.7 \mathrm{~min}$ of data collection can be represented by a line: $y=3.6-0.64 t\left(r^{2}=0.988\right)$. Between 1 and $10 \mathrm{~min}$ of exchange, the rate slows and is described by $\mathrm{y}=3.2-0.034 \mathrm{t}\left(\mathrm{r}^{2}=0.994\right)$, corresponding to a population exchanging with a half-life of $20 \mathrm{~min}$. Finally, from 10 to $55 \mathrm{~min}$ is a region described by $y=3.0-0.012+\left(r^{2}=0.997\right)$. This translates to a population of protons exchanging with a half-life of 50 min. At the first time point we can measure, 36 of the 70 exchangeable protons of Ala-bGRF have exchanged. The fast-exchanging protons have a rate similar to that seen in melittin and probably also represent side-chain and terminal protons. The slowly-exchanging populations, those with half-lives of 20 or $50 \mathrm{~min}$, may be those involved in hydrogen bonds.

This type of analysis would suggest that the hydrogen bonding of $\Lambda$ la bGRF is more stable, under our conditions, than that of melittin. It is worth noting that the relative stability of helices is not information readily available from other spectroscopic measurements. $C D$ provides a time-averaged percent helix, but gives no direct information about stability. NMR can provide stability data, but consumes a considerable amount of time and material. Both melittin and AlabGRF are known from other studies to be $\alpha$-helical [12, $13,15]$. No other type of secondary structure is present.

\section{MS / MS}

Although the information from the deuterium exchange experiments described above is useful for determining the relative stability of peptides, one cannot establish the location of the incorporated deuterium atoms from the change in mass alone. We therefore considered analyzing the sample by MS/MS during the exchange. In an MS/MS experiment one normally selects a precursor ion using MS- 1 , collisionally activates it in a region of relatively high pressure between MS-1 and MS-2, and then observes the product (fragment) ions by scanning the second mass filter, MS-2 [22]. For peptides, the polyamide backbone fragments in a predictable way to give rise to several series of ions from which much of the sequence can be deduced [23]. MS /MS spectra of the +4 charged ion of melittin and the +4 charged ion of Ala-bGRF are shown in Figure 4. Much sequence information is evident and is summarized in Tables 1 and 2. Because we selected a multiply-charged precursor ion in each case, the product ions can also be multiply charged, somewhat complicating the interpretation, but most ions can be assigned to the b- or $y$-ion series. MS/MS experiments were first performed on the undeuterated peptide, and then on a fully exchanged peptide that had been al-
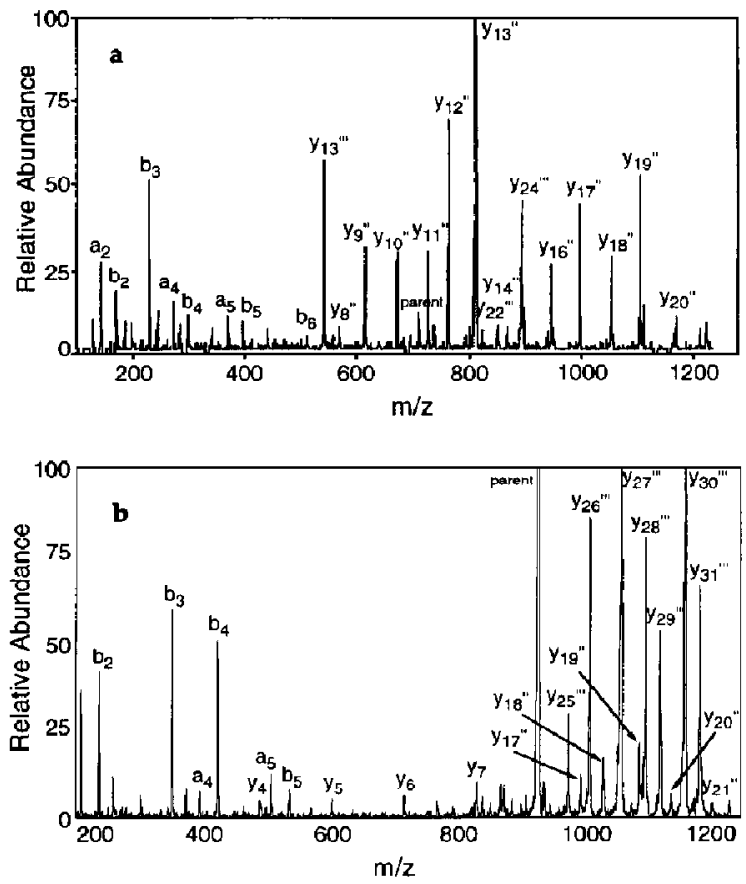

Figure 4. Product ion spectra (MS/MS) resulting from collisional activation of the +4 charge state of melittin $(m / z$ 712) (a) and Ala-bGRF ( $m / z$ 924) (b). Sequence ions are labeled with double or triple quotes to indicate the +2 or +3 charge state, respectively.

lowed to exchange for two hours prior to MS / MS. The mass of the intact peptide and the mass shifts in the product ions were consistent with those expected on the basis of our assignments. Complete sequence data was not obtained in melittin or Ala-bGRF, but in both cases information was present representing the Nterminal region, the $\mathrm{C}$-terminal region, and the middle portion of the peptide. This was sufficient for us to assess the existence and stability of a possible $\alpha$-helix in each of these regions.

The charge observed on a peptide in the ESI mass spectrum correlates roughly with the number of basic residues [24], and it is interesting to note that some correlation holds for the product ions as well. For example the $y_{5}$ and $y_{6}$ ions in Ala-bGRF have a single basic residue (Arg-29), and are both singly charged (Table 2). The $\mathrm{y}_{15-19}$ ions are all doubly charged and include, in addition to Arg-29, a double-basic sequence Arg-Lys (residues 20-21]. The $y_{24-29}$ ions are all triply charged and contain basic sequences at Arg-11-Lys-12, Arg-20-Lys-21, and Arg-29.

To obtain additional information on sequences of melittin that were not initially represented by product ions, we took advantage of the appearance of an "internal" fragment ion. The presence of a Pro residue at position 14 gives rise to a facile peptide bond between Leu-13 and Pro-14. By increasing the energy of the incoming ions (increasing the "orifice potential"), we 
Table 1. The observed sequence ions from collision-induced dissociation (CID) on the +4 charge state of melittin and the deuterium incorporation as a function of time

\begin{tabular}{|c|c|c|c|c|c|c|c|}
\hline \multirow[b]{2}{*}{ Ion } & \multirow{2}{*}{$\begin{array}{l}\text { Protonated } \\
\text { Mass (Da) }\end{array}$} & \multirow{2}{*}{$\begin{array}{c}\text { Deuterated } \\
\text { Mass (Da) }\end{array}$} & \multicolumn{5}{|c|}{$\begin{array}{l}\text { Average Number of Labile Hydrogens } \\
\text { Remaining after Time } t \text { (min) }\end{array}$} \\
\hline & & & 0 & 0.5 & 2 & 5 & 10 \\
\hline \multicolumn{8}{|c|}{ Singly charged } \\
\hline$b_{2}$ & 170.8 & 174.2 & 3 & 1.0 & 0.4 & 0.2 & 0.2 \\
\hline$b_{3}$ & 228.0 & 231.8 & 4 & 1.3 & 0.8 & 0.4 & 0.2 \\
\hline$b_{4}$ & 299 & 304 & 5 & 1.6 & 1.1 & 0.2 & 0.2 \\
\hline$b_{5}$ & 398.2 & 404 & 6 & 2.4 & 1.4 & 0.6 & 0.5 \\
\hline$b_{6}$ & 511.6 & 518.6 & 7 & 3.1 & 2.0 & 1.6 & 1.0 \\
\hline$b_{7}$ & 639.5 & 649.8 & 10 & 4.0 & 2.8 & 1.8 & 1.0 \\
\hline$b_{12}$ & 1110.3 & 1127.2 & 17 & 7.0 & 4.8 & 2.8 & 1.6 \\
\hline$b_{13}$ & 1224.2 & 1241.5 & 18 & 7.1 & 5.1 & 3.1 & 1.3 \\
\hline \multicolumn{8}{|c|}{ Doubly charged } \\
\hline$y_{10}$ & 1342.2 & 1372.4 & 32 & 12.8 & 9.0 & 6.0 & 5.0 \\
\hline$Y_{11}$ & 1455 & 1487.6 & 33 & 13.2 & 10.0 & 6.8 & 5.2 \\
\hline$y_{12}$ & 1526.6 & 1569.6 & 34 & 13.6 & 10.4 & 7.4 & 5.3 \\
\hline$y_{13}$ & 1623.8 & 1657 & 34 & 12.8 & 10.6 & 7.4 & 5.2 \\
\hline$y_{14}$ & 1737 & 1772.6 & 35 & 13.3 & 10.8 & 7.4 & 5.4 \\
\hline$Y_{15}$ & 1794.2 & 1829 & 36 & 13.8 & 10.6 & 9.4 & 5.6 \\
\hline$Y_{16}$ & 1895 & 1932.4 & 38 & 14.8 & 12.4 & 8.4 & 5.8 \\
\hline$y_{17}$ & 1996.2 & 2035 & 40 & 15. B & 12.6 & 9.0 & 6 \\
\hline$y_{18}$ & 2109.8 & 2151 & 41 & 17.0 & 13.4 & 9.0 & 5.8 \\
\hline$Y_{19}$ & 2209 & 2250.4 & 42 & 17.4 & 12 & 8.8 & 5.6 \\
\hline$y_{20}$ & 2336.6 & 2379.4 & 45 & 18.4 & 12.6 & 8.8 & 6.0 \\
\hline \multicolumn{8}{|c|}{ Triply charged } \\
\hline$y_{22}$ & 2550.4 & 2591.9 & 47 & 17.1 & 13.5 & 8.7 & 6.2 \\
\hline$y_{23}$ & 2620.6 & 2663.9 & 48 & 18.0 & 14.7 & 8.1 & 5.7 \\
\hline$y_{24}$ & 2677 & 2724.5 & 49 & 18.9 & 15.3 & 9.9 & 7.5 \\
\hline
\end{tabular}

Table 2. The observed sequence ions from CID on the +4 charge state of Ala-bGRF and the deuterium incorporation as a function of time

\begin{tabular}{|c|c|c|c|c|c|c|c|}
\hline \multirow[b]{2}{*}{ Ion } & \multirow{2}{*}{$\begin{array}{l}\text { Protonated } \\
\text { Mass (Da) }\end{array}$} & \multirow{2}{*}{$\begin{array}{l}\text { Deuterated } \\
\text { Mass (Da) }\end{array}$} & \multicolumn{5}{|c|}{$\begin{array}{c}\text { Average Number of Labile Hydrogens } \\
\text { Remaining at Time t (min) }\end{array}$} \\
\hline & & & 0 & 0.5 & 6 & 8 & 10 \\
\hline \multicolumn{8}{|c|}{ Singly charged } \\
\hline$b_{2}$ & 235 & 238.7 & 4 & 0.6 & 0.2 & 0.2 & 0.2 \\
\hline$b_{3}$ & 350 & 355.7 & 6 & 1.0 & 0.2 & 0.2 & 0.2 \\
\hline$b_{4}$ & 420.8 & 427.7 & 7 & 1.3 & 0.2 & 0.5 & 0.5 \\
\hline$b_{5}$ & 534 & 540.2 & 8 & 0.8 & 0.6 & 0 & 0 \\
\hline$y_{5}$ & 6012 & 6197 & 19 & 4.8 & 2.1 & 1.2 & 0.7 \\
\hline$Y_{6}$ & 714.2 & 734.8 & 20 & 5.3 & 2.5 & 1.3 & 0.6 \\
\hline \multicolumn{8}{|c|}{ Doubly charged } \\
\hline$y_{15}$ & 1739.2 & 1778.0 & 39 & 12.4 & 6.0 & 4.0 & 2.5 \\
\hline$y_{16}$ & 1852.6 & 1892.0 & 40 & 12.9 & 5.4 & 4 & 2.4 \\
\hline$Y_{17}$ & 1980.2 & 2021.6 & 43 & 13.7 & 5.6 & 3.9 & 1.6 \\
\hline$y_{18}$ & 2052.2 & 2095.6 & 44 & 14.1 & 5.6 & 4.0 & 2.6 \\
\hline$y_{19}$ & 2165.8 & 2209.4 & 45 & 14.5 & 6.0 & 4.1 & 2.4 \\
\hline \multicolumn{8}{|c|}{ Triply charged } \\
\hline$Y_{24}$ & 2797.6 & 28550 & 58 & 19 & 7.5 & 5.4 & 3.9 \\
\hline$Y_{25}$ & 2914.0 & 2972.0 & 61 & 19.8 & 7.5 & 5.4 & 3.6 \\
\hline$Y_{2 B}$ & 3013.6 & 3075.5 & 63 & 20.2 & 7.8 & 5.3 & 3.9 \\
\hline$Y_{27}$ & 3161.2 & 3224.0 & 64 & 20.5 & 7.5 & 5.1 & 3.9 \\
\hline $\mathrm{Y}_{28}$ & 3274.0 & 3338.3 & 65 & 20.7 & 7.8 & 5.3 & 3.9 \\
\hline$y_{29}$ & 3344.2 & 3410.3 & 66 & 20.8 & 7.5 & 5.6 & 4.1 \\
\hline
\end{tabular}




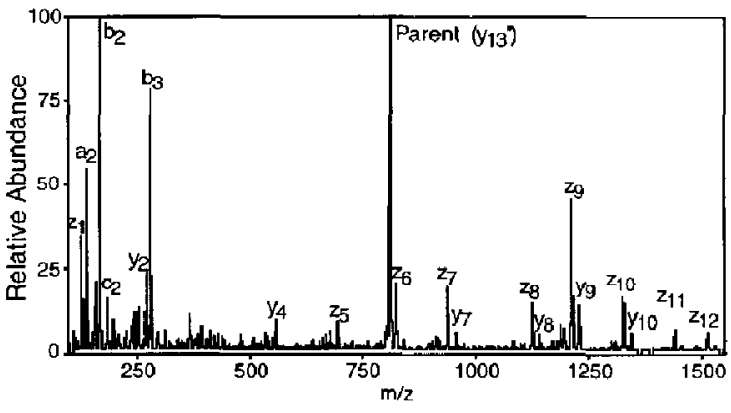

Figure 5. Product ion mass spectrum of the $y_{13}^{+2}$ ion $(m / z$ 813) from melittin.

could enhance the formation of this $y_{13}$ ion in the free jet expansion region of the mass spectrometer before the first quadrupole. By selecting this doubly charged fragment ion $(m / z$ 813) with MS-1 and collisionally activating as before, we could induce further fragmentation (second generation product ions). Because the selected precursor was smaller than the original precursor, fragmentation was more efficient, and a more complete set of sequence ions was obtained. Using only the data from the MS/MS of intact melittin, the sequence information at the $\mathrm{C}$-terminus of the peptide was incomplete (Table 1). The $y_{10}$ ion was as far as the sequence ions could be interpreted. By forming and mass-selecting the $\mathrm{y}_{13}$ ion (Figure 5), fragment ions were generated to allow the deuterium atoms to be located out to the penultimate residue at the $\mathrm{C}$ terminus (Table 3 ).

To study the stability of the helix in our two model peptides, we sought to conduct the MS/MS experiments during the deuterium exchange of the peptide. By observing where the deuterium atoms were exchanging as a function of time, we felt we would be able to assess the stability of various regions of the helix. Those experiments proved difficult to do, partic- ularly in the early time points, when the mass of the precursor ion was changing very rapidly. We consequently defocused MS-1 so that a wide range of massto-charge ratio values (10-15 Da) would be transmitted, surrounding the precursor ion of interest. As the mass of the peptide changed because of deuterium incorporation, the mass of the precursor ion changed, but stayed within the window transmitted by MS-1; and product ions could be continuously monitored.

The number of deuterium atoms in any given product ion was determined from comparing the observed mass-to-charge ratio with that of the same ion derived from the fully protonated and the fully deuterated counterparts. These results are tabulated in Tables 1-3 as the number of hydrogens remaining (i.e., not $e x-$ changed). Presumably the regions that are not exchanging are those positions where the hydrogen bonds are most stable, and are indicative of regions still involved in the $\alpha$-helix. (In the peptide systems chosen, no other form of secondary structure, for example $\beta$-sheet, is present. If several different types of structure were present, the MS/MS could not distinguish between them.) It is evident from looking at Tables 1-3 that for any given sequence ion, the degree of deuteration increases with time. That is, the number of hydrogens remaining in the fragment decreases as one moves from left to right in the table.

To display the data in a more graphic format, the number of hydrogens remaining in any product ion was transformed to an estimate of whether or not a particular amide hydrogen was involved in hydrogen bonding. To do this, the change in the number of hydrogens per residue was calculated and represented in the circle diagrams of Figures 6 and 7. For example, the $y_{19}$ ion in melittin has an average of 12 exchangeable hydrogens remaining after $2 \mathrm{~min}$ (Table 1), the $\mathrm{y}_{20}$ ion has an average of 12.6 hydrogens remaining. The difference between these two positions is the addition of the residue corresponding to Lys-7, the residue 20

Table 3. The observed second generation sequence ions from CID on the $y_{13}^{+3}$ ion of melittin and the deuterium incorporation as a function of time

\begin{tabular}{|c|c|c|c|c|c|c|c|}
\hline \multirow[b]{2}{*}{ Ion } & \multirow{2}{*}{$\begin{array}{l}\text { Protonated } \\
\text { Mass (Da) }\end{array}$} & \multirow{2}{*}{$\begin{array}{l}\text { Deuterated } \\
\text { Mass (Da) }\end{array}$} & \multicolumn{5}{|c|}{$\begin{array}{l}\text { Average Number of Labilc Hydrogens } \\
\text { Remaining after Time t (min) }\end{array}$} \\
\hline & & & 0 & 0.5 & 2 & 5 & 10 \\
\hline$z_{1}$ & 129 & 132.8 & 4 & 1.4 & 0.8 & 0.6 & 0.4 \\
\hline $\mathbf{b}_{2}$ & 169 & 170.8 & 2 & 1.2 & 0.6 & 0.2 & 0 \\
\hline$v_{2}$ & 268 & 279 & 10 & 2.6 & 1.2 & 0.6 & 0.4 \\
\hline$b_{3}$ & 282 & 285 & 3 & 1.6 & 1.0 & 0.6 & 0.4 \\
\hline $\mathrm{V}_{4}$ & 558 & 575.8 & 18 & 7.2 & 5.6 & 3.4 & 2.4 \\
\hline$z_{5}$ & 696.8 & 715.8 & 20 & 9.0 & 6.0 & 4.0 & 3.2 \\
\hline$z_{6}$ & 825.4 & 848 & 23 & 10.0 & 7.4 & 4.3 & 3.6 \\
\hline$z_{7}$ & 938.6 & 962.5 & 24 & 10.8 & 8.0 & 4.8 & 3.9 \\
\hline$z_{8}$ & 1125 & 1150.5 & 26 & 11.3 & 8.6 & 5.6 & 4.2 \\
\hline$z_{9}$ & 1212 & 1240 & 28 & 12.0 & 9.0 & 6.2 & 4.0 \\
\hline$z_{10}$ & 1325.4 & 1353.8 & 29 & 13.0 & 9.4 & 6.2 & 4.4 \\
\hline$z_{11}$ & 1438.2 & 1468.3 & 30 & 13.5 & 8.7 & 6.1 & 4.5 \\
\hline$z_{12}$ & 1509.6 & 1540.3 & 31 & 14.4 & 9.8 & 7.2 & 5.8 \\
\hline
\end{tabular}




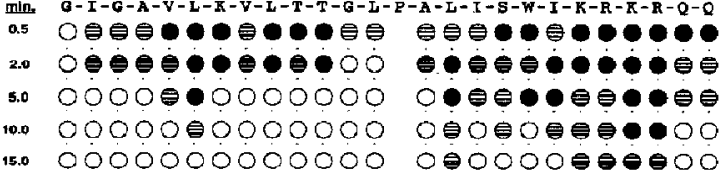

Figure 6. Circle diagram showing the deuterium exchange of melittin. Each row of circles represents a different point in time, as indicated on the left. Each circle indicates the extent of exchange for the amide proton at that position (amine, in the case of position 1). Open circles (O) represent protons that have exchanged; filled circles (O) represent protons that have not exchanged; shaded circles $(\Theta$ ) represent an intermediate condition. See text for details of the calculation. The proline in position 14 is a secondary amide and thus has no amide proton.

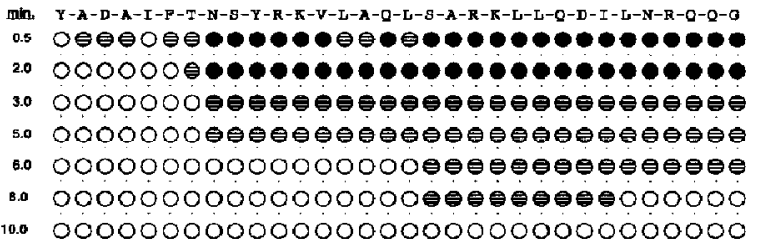

Figure 7. Circle diagram showing the deuterium exchange of Ala-bGRF. Each row of circles represents a different point in time, as indicated on the left. Each circle indicates the extent of exchange for the amide proton at that position (amine, in the case of position 1). Open circles (O) represent protons that have exchanged; filled circles (O) represent protons that have not exchanged; shaded circles $(\theta)$ represent an intermediate condition. See text for details of the calculation.

positions from the C-terminus. We would therefore conclude that the increase of 0.6 unexchanged hydrogens is due to the amide hydrogen of Lys-7 because we would assume the $\epsilon$-amine protons on Lys would exchange roughly 100 times faster than the amide proton at this $\mathrm{pH}$ (3.2). The value of 0.6 suggests that the amide proton is partially, but not fully, exchanged, and is therefore probably involved in hydrogen bonding. In the circle diagram, we represent amides with an incremental increase of 0.6 or more with a filled circle.

Other regions, for example, the difference between $y_{14}$ and $y_{15}$ in melittin at 2 min of exchange (Table 1), show little or no increase in the average number of exchangeable hydrogens remaining, and presumably indicate that the amide proton at that position (Gly-12) is already deuterated, and therefore unlikely to be involved in a hydrogen bond. Values of the incremental hydrogen increase for an individual position of less than 0.3 are represented in the circle diagrams as open circles. Values between 0.6 and 0.3 are represented as shaded circles. To smooth some of the scatter in the numbers from $y$-series ions, a rolling average was taken for the melittin data.

For gaps in the sequence, the difference between the average numbers of hydrogens remaining at both ends of the gap was divided by the number of amino acid residues in the gap, leading to an average increase per residue. The degree of filling of the circles representing these residues follows the same rules as above. The results of all of these calculations are shown diagrammatically in Figures 6 and 7 for melittin and Ala-bGRF, respectively. Open circles represent regions where exchange has occurred, that is, areas where the helix has unfolded and exchange has occurred. Filled circles indicate regions where exchange has not occurred, and where we would propose that the peptide is still helical. Shaded circles represent some intermediate condition.

It is evident that over time an increasing portion of the helix has unfolded, as would be predicted, both on the basis of the continued increase in overall mass of the peptide and by studies of deuterium exchange by other methods. The exchange data for melittin (Tables 1 and 3 and Figure 6) show two distinct helical regions with a kink in the middle around Pro-14. As we have indicated before [10], the first four amide bonds in a helix have no corresponding carbonyl partners for hydrogen bonding, and so would be expected to be in relativcly fast cxchange with the solvent. Helical segments indicated in Figures 6 and 7 probably extend several residues to the $\mathrm{N}$-terminal side of the last shaded circle. The proline at position 14 seems to put a kink in the melittin helix. Even at the earliest time points, exchange is more rapid around residues 12-15 (proline itself has no amide hydrogen to exchange or to participate in hydrogen bonding). This observation is consistent with the known helix-destabilizing character of proline [25]. NMR studies predict helices from residues 2 to 11 and from residues 13 to 26 [12] in complete agreement with the mass spectrometric data.

The ESI/MS data can also predict the stability of the helix over time. As one moves down Figure 6, it is evident that the extent of deuterium exchange is increasing (more open circles). This is presumably because the helix is unwinding, allowing deuterated solvent access to amides that were hydrogen bonding. We cannot measure with deuterium exchange whether or not the helix has refolded; once it unfolds and exchanges, it continues to be measured as "unfolded." Presumably the folding is a dynamic process and continual unfolding and refolding are constantly occurring. The helical segment of melittin to the N-terminal side of Pro-14 is less stable than the C-terminal helix. After about $10 \mathrm{~min}$, the entire $\mathrm{N}$-terminal helix has exchanged (all circles open), while the C-terminal helix persists beyond the $15 \mathrm{~min}$ shown in Figure 6 . These predictions are consistent with NMR studies on the stability of melittin, which also show the C-terminal helix to be more stable $[13,26]$.

The data for the exchange of Ala-bGRF (Table 2 and Figure 7) show a somewhat different pattern. A long helical region in the early time points extends nearly the entire length of the peptide. CD of this peptide suggests that it is about $80 \%$ helical in $80 \%$ organic 
solvent [10]. Our ESI/MS data would predict about $90 \%$ in the earliest time point. It is here that the information from mass spectrometry and $C D$ are nicely complementary. $C D$ gives a time-averaged, static measure of helical content, mass spectrometry provides a more dynamic, kinetic measure of stability. We have demonstrated this complementarity elsewhere for other peptides (Wagner, D. S.; Melton L. G.; Yan, Y.; Erickson, B. W.; Anderegg, R. J. Unpublished results).

The helix in Ala-bGRF seems to unfold from both ends of the peptide, but more rapidly from the $\mathrm{N}$ terminus than from the C-terminus, as evidenced by the more rapid exchange in the $\mathrm{N}$-terminal region (more open circles in Figure 7). The region around Ser-18 to Ile-26 is the last part of the helix to exchange, presumably because it is the most stable. Complete exchange occurs in about ten $\mathrm{min}$, at least as far as we can determine. The open circles in Figure 7 only indicate a value of less than 0.3 hydrogens remaining per residue. Over the length of the peptide, we know there are still a few hydrogens remaining, but the location of these cannot be determined from the data presented here. It is evident from the time-course data in Figure $3 \mathrm{~b}$ that hydrogens still remain after $10 \mathrm{~min}$.

While the data for the Ala-bGRF and melittin experiments are encouraging, some care must be exercised in their interpretation. Most of the information on these two peptides comes from y-series sequence ions. These ions are formed with the transfer of two hydrogen atoms to the nascent terminal amine. One of these hydrogens presumably is from the protonating solvent and would therefore be expected to be a deuterium atom. The other comes from an amide to the N-terminal side of the cleaving bond [27]. In our experiments this will lead to a potential crror, in that we can never be certain from where the transferred hydrogen comes, and therefore whether it is a deuterium or a protium atom. If we assume that geometric arguments outweigh possible isotope effects, the transferred atom would come from a nearby amide. While this will lead to some apparent local scrambling of the deuterium, it should not greatly alter the overall picture of where the helix is unwinding. This uncertainty may be the cause of the apparent anumalies in the clata in Tables 1-3, where occasionally it appears that the number of hydrogens remaining in a fragment decreases even though the size of the fragment increases.

For peptides where the predominant ion series is the b-series there should be no such confusion. Indeed, it might be advantageous to derivatize peptides to encourage a- and b-ion series formation [28], if it can be done without altering the peptide's conformation.

Many of the ions from which we derive information are multiply charged product ions. As with other ESI/MS experiments, the mass-to-charge ratio assignment of the multiply charged ions takes on added importance, because errors in mass-to-charge ratio assignment are multiplied by a factor of the charge. Even the round-off error applied by the data system will be magnified. Here again, the limitation does not change the overall conclusions about location of secondary structure, but introduces some measure of uncertainty about the ends of the helix, in that the arbitrary crossover points between different levels of shading will be uncertain.

As the size of the peptide increases, the completeness of sequence information tends to decrease [29]. While a small peptide $(<10$ residues) might give a complete series of ions, peptides of 30 or more residues rarely do. This has two consequences. It limits the ultimate size of the peptide that will be accessible to the technique, and it creates gaps in the sequence for which only an average extent of exchange can be inferred. In our hands, peptides greater than about 30 residues have insufficient sequence data to provide a clear picture of secondary structure. To some extent, the use of second generation product ions can be used to overcome this difficulty, as was used above for melittin. However, this adds one more experiment to the process for each additional precursor ion selected, and in many cases a facile fragment may not readily form, as was observed in Ala-bGRF. In these cases, second generation product ions may be too weak to provide useful data.

\section{Conclusions}

The use of deuterium exchange in combination with electrospray tandem mass spectrometry can provide important information regarding the location and stability of secondary structure within peptides. It requires very little sample $(<500 \mathrm{pmol} /$ experiment) relative to the quantities used in NMR and is quite fast. For peptides of the size described here, exchange was monitored for about $60 \mathrm{~min}$; for larger proteins with more secondary structure, exchange will proceed more slowly, and a consequently longer observation time will be required. Data analysis is currently cumbersome because each product ion must be analyzed separately for its degree of deuterium incorporation; but much of that process is routine calculation and should be able to be performed by the computer in an automated manner.

We feel confident in comparing the relative exchange rates of peptides in a variety of solution conditions (e.g., $\mathrm{pH}$, organic solvent concentration, etc.). Other types of secondary structure (e.g., $\beta$-sheets) are also amenable to the technique (Wagner, D. S.; Melton, L. G.; Yan, Y.; Erickson, B. W.; Anderegg, R. J. Unpublished results), although it is unlikely that we will be able to differentiate between various types of structure by mass spectrometry alone. It should be possible, however, to extend this technique to look at peptides in the presence of proteins to which they bind in an effort to locate hydrogen bonds that might indicate points of contact in a protein:ligand interaction. 


\section{Acknowledgments}

The authors gratefully acknowledge T. Kubiak and A. Friedman of the UpJohn Company for samples of Ala-bGRF.

\section{References}

1. Felix, A. M.; Heimer, E. P.; Mowles, T. F.; Eisenbeis, H.; Laing, P.; Lambros, T. J.; Ahmad, M.; Wang, C. T.; Brazeau, P. Proc. of the 19th European Peptide Symp.; Theodoropoulis, D., Ed. 1987, pp. 481-484.

2. Dempsey, C. E. Biochim. Biophys. Acta 1990, 1031, 143-161.

3. Kaiser, E. T.; Kedzy, F. J. Science 1984, 223, 249-255.

4. Creighton, T. E. Proteins: Structures and Molecular Principles, W. H. Freeman and Co.: New York, 1984, pp. 265-333.

5. Finglander, S. W.; Kallenbarh, N. R. Quart. Rear. Biophys. 1984, $16,521-655$.

6. Katta, V.; Chait, B. T. Rapid Commun. Mass Spectrom. 1991, 5 , 214-217.

7. Zhang, Z.; Smith, D. L. Prot. Sct. 1993, 2, 522-531.

8. Suckau, D.; Shi, Y.; Beu, S. C.; Senko, M. W.; Quinn, I. P.; Wampler, F. M. III; McLafferty, F. W. Proc. Natl. Acad. Sci. USA 1993, 90, 790-793.

9. Miranker, A.; Robinson, C. V.; Radford, S. E.; Aplin, R. T,; Dobson, C. M. Science 1993, 262, 896-900.

10. Stevenson, C. L.; Anderegg, R. J.; Borchardt, R. T. I. Amer. Soc. Mass Spectromt. 1993, 4, 646-651.

11. Thevenon-Emeric, G.; Kozlowski, J.; Zhang, Z.; Smith, D. L. Anal. Chem. 1992, 64, 2456-2458.

12. Bazzo, R.; Tappin, M. J.; Pastore, A.; Harvey, T. S.; Carver, J. A.; Campbell, I. D. Eur. J. Biochem. 1988, 173, 139-146.

13. Dempsey, C. B. Biochemistry 1988, 27, 6893-6901.
14. Vance, M. L. Clin. Chem. 1990, 36, 415-420.

15. Fry, D. C.; Madison, V. S.; Greeley, D. N.; Felix, A. M.; Heimer, E. P.; Froliman, L.; Campbell, R. M.; Mowles, T. F.; Toome, V.; Wegrzynski, B. B. Bioploymers 1992, 32, 649-666.

16. Brunger, A. T.; Clore, G. M.; Gronenborn, A. M.; Karplus, M. Protein Engineering 1987, 5, 399-406.

17. Tou, J. S.; Kaempfe, L. A.; Vineyard, B. D.; Buonomo, F. C.; Della-Fera, M. A.; Baile, C. A. Biochem. Biophys. Res. Commun. 1986, 139, 763-770.

18. Kloosterman, D. A.; Scahill, T. A; Hillman, R. M.; Clẹary, D. L.; Kubiak, T. M. Peptide Res. 1991, 4, 72-78.

19. Fenn, J. B.; Mann, M.; Meng, C. K.; Wong, S. F.; Whitehouse, C. M. Mass Spectrom. Reo. 1990, 9, 37-70.

20. Covey, T. R.; Bonner, R. F.; Shushan, B. I.; Henion, J. D. Rapid Commun. Mass Spectrom. 1988, 2, 249-256.

21. Mann, M.; Meng, C. K.; Fenn. I. B. Anal. Chem. 1989, 61 , 1702-1708.

22. Hunt, D. F.; Yates, J. R. III; Shabanowitz, J.; Winston, S.; Hauer, C. R. Proc. Natl. Acad. Sci. USA 1986, 83, 6233-6237.

23. Biemann, K; Martin, S. A. Mass Spectrom. Kev. 1987, 6, 1-76.

24. Loo, J. A.; Edmonds, C. G.; Udseth, H. R.; Smith, R. D. Anal. Chem. 1990, 62, 693-698.

25. Chou, P. Y.; Fasman, G. D. Biochemistry 1974, 13, 222-245.

26. Pastore, A.; Harvey, T. S.; Dempsey, C. E.; Campbell, I. D. Eur. Biophys. I. 1989, 16, 363-367.

27. Kenny, P. T. M.; Nomoto, K.; Orlando, R. Rapid Commun. Mass Spectrom. 1992, 6, 95-97.

28. Stults, J. T. Proceedings of the 40th Arrual ASMS Conference on Mass Spectrometry and Allied Topics; Washington, D.C., May 31-June 5, 1992; pp. 1815-1816.

29. Smith, R. D; Loo, J. A; Edmonds, C. G; Barinaga, C. J.; Udseth, H. R. Anal. Chem. 1990, 62, 882-899. 